\title{
The relationship between body mass index and body image in Brazilian adults
}

\author{
Idalina S. Kakeshita and Sebastião Sousa Almeida \\ Universidade de São Paulo, Ribeirão Preto, Brazil
}

\begin{abstract}
The aim of this work was to assess the relationship between nutritional status and body image perception in Brazilian adults. Participants included 280 adults (18-60 years) of both genders. The sample was composed proportionally to the Brazilian nutritional status distribution according to body mass index, with volunteers of all economic classes and educational levels. We applied a Figure Rating Scale to examine body image concerning size and shape. Both men and women were dissatisfied with their body size. Regarding body discrepancy, eutrophic adults overestimated their body size and desired leaner bodies. Our results also showed that the higher the BMI, the smaller the differences between men and women. These findings reinforce that body image perception is an important factor to be considered by health professionals in order to improve quality of life. Keywords: Body mass index, body image, body discrepancy.
\end{abstract}

Received 10 September 2008; received in revised form 21 November 2008; accepted 04 December 2008. Available online 22 December 2008

\section{Introduction}

The study of body image among normal populations has greatly increased over recent years (Tehard, Van Liere, Com Nougue \& Clavel-Chapelon, 2002; Kakeshita \& Almeida, 2006). It is also known that body image is a multi-dimensional construct with the implication of several variables (Thompson, 2004) and a large number of instruments have been developed to assess this construct (Thompson, 1996).

Previously, the studies focused on factors associated with body image disturbances related to neuropathological forms of body experiences, from a psychoanalytic perspective (Cash, 2004). Body image perception was assessed in both eating disordered (Matos et al., 2002; Vander Wal \& Thomas, 2004; Legenbauer, Rühl \& Vocks, 2008) and body dysmorphic disordered populations. Nowadays, research on body image has mostly focused on body image dissatisfaction among the normal population (Fingeret, Gleaves \& Pearson, 2004; McCabe, Ricciardelli, Sitaram \& Mikhail, 2006; Van Den

Idalina S. Kakeshita and Sebastião de Sousa Almeida, DepartamentodePsicologiaeEducação, FaculdadedeFilosofia, Ciências e Letras de Ribeirão Preto, Universidade de São Paulo, Brazil. Correspondence regarding this article should be directed to: Sebastião de Sousa Almeida, Laboratório de Nutrição e Comportamento do Departamento de Psicologia e Educação da Faculdade de Filosofia, Ciências e Letras de Ribeirão Preto. Av. Bandeirantes, 3900 - Monte Alegre - Ribeirão Preto - SP CEP 14040-901. E-mail: sebasalm@usp.br
Berg et al., 2007; Neighbors \& Sobal, 2007) in order to identify discrepancies in body image perception (Cachelin, Monreal \& Juarez, 2006; Steenhuis, Bos \& Mayer, 2006), which have been considered for the prevention and the treatment of a variety of other disorders (Matos et al., 2002), especially the ones involving behavioral changes (Lynch, Heil, Wagner \& Havens, 2008) and/or the promotion of well-being and quality of life (Damasceno, Lima, Vianna, Vianna \& Novaes, 2005).

In spite of the development of a large number of instruments (Thompson, 1996), the Figure Rating Scale has still been the most used tool for the assessment of body size and weight-related components of body image (Tehard, Van Liere, Com Nougué \& Clavel-Chapelon, 2002; Fingeret, 2004; Sánchez-Johnsen, Hogan, Wilkens \& Fitzbbon, 2008; Swami, Salem, Furnham \& Tovée, 2008). It is a simple, low cost instrument which does not require the use of high technology equipment.

The aim of this study was to assess body image perception in a Brazilian adult sample according to the nutritional status classified by the body mass index (BMI) using the Figure Rating Scale, which was developed by our group and had its reliability and validity previously tested in the Brazilian context (Kakeshita, 2008).

\section{Methods}

\section{Participants}

The initial idea was to recruit 20 volunteers belonging to the BMI interval corresponding to each of the silhouettes of the scale to be used, totalizing 600 participants of each 
Table 1. Brazilian BMI distribution by gender, and minimal adult needed to represent all BMI classes.

\begin{tabular}{|c|c|c|c|c|c|c|}
\hline \multicolumn{7}{|c|}{ ADULT SAMPLE } \\
\hline \multicolumn{3}{|c|}{ FEMALE } & & \multicolumn{3}{|c|}{ MALE } \\
\hline \multicolumn{3}{|c|}{ Percentage } & & \multicolumn{3}{|c|}{ Percentage } \\
\hline Sample & On Population & Proposed & BMI & Sample & On Population & Proposed \\
\hline 3 & $5 \%$ & $5 \%$ & $<8$ & 1 & $2 \%$ & $2 \%$ \\
\hline 26 & $42 \%$ & $42 \%$ & $18-24.99$ & 24 & $44 \%$ & $44 \%$ \\
\hline 25 & $40 \%$ & $40 \%$ & $25-29.99$ & 24 & $44 \%$ & $44 \%$ \\
\hline 7 & $11 \%$ & $11 \%$ & $30-39.99$ & 5 & $8 \%$ & $8 \%$ \\
\hline 1 & $2 \%$ & $2 \%$ & $>40$ & 1 & $2 \%$ & $2 \%$ \\
\hline Total: 62 & & & & Total: 55 & & \\
\hline
\end{tabular}

gender. This proposal was not possible due to the low occurrence of representative adults of the silhouettes in the lower end of the scale within the normative population. Some participants would have to be contacted in specific programs for people with Anorexia Nervosa.

Therefore, in order to guide a feasible outlining, we decided to search for statistical data of the Brazilian population according to their BMI distribution. To this end, the nutritional status classification based on the anthropometric measures of the last Family Expenditure Survey (POF-2002-2003) of the Brazilian Institute of Geography and Statistics (IBGE, 2004) was used. Thus, the minimal sample size contained people representing the BMI classes according to the World Health Organization (WHO, 1997) (Table 1) and each BMI interval of the Figure Rating Scale (Kakeshita, 2008).

This research was carried out at the urban zone of two cities in the countryside of the state of São Paulo (Brazil). Participants were recruited in a variety of places, such as colleges and health and recreation centers. A similar percentage of men and women $(50.71 \%$ and $49.29 \%$, respectively), of different ages, socioeconomic status, educational level and BMI classes were included.

The data collection began as soon as the Ethics Committee of the Faculty of Philosophy, Sciences and Letters of Ribeirão Preto, University of São Paulo, approved the research. Data from 311 adults between the ages of 18-59(163 women and 148 men) were collected. Data from below-normal BMI and morbid obese participants were excluded, given that their low representativeness percentage could bias the statistical analysis (see Table 1). The final convenient sample was composed by 280 volunteers (138 women and 142 men).

\section{Apparatus}

The Figure Rating Scale developed by Kakeshita (2008) was used. This scale consists of 15 cards depicting each gender with drawings of silhouettes.
Each silhouette represents a BMI interval with mean values of BMI ranging from $12.5 \mathrm{~kg} / \mathrm{m}^{2}$ to $47.5 \mathrm{~kg} / \mathrm{m}^{2}$. Participants' weight and height were measured using an electronic calibrated scale and a portable anthrop meter (Kratos-Cas, Brazil).

\section{Procedure}

All participants gave signed informed consent. Personal and social demographic data were collected. Presented with the scale of their own gender in ascending order, from very thin to very large silhouettes, the participants were required to indicate which figure best represented their current and desired body size, as well as the figure they believed to be the ideal body size in general. After measuring their weight and height, we calculated their actual BMI. The difference between current and actual BMI was considered body discrepancy, and the difference between desired and actual BMI was considered body dissatisfaction. The current BMI is the BMI represented by the figure indicated by the participants as representing their actual body size. The actual BMI is the BMI calculated based on the weight and height of the participants.

\section{Statistics}

The data were analyzed using the software SPSS 13.0. A two-way analysis of variance (ANOVA) was performed to analyze the effect of gender and BMI class (normal, overweight, obese) on body image discrepancy and dissatisfaction, examining differences between current, desired and actual BMI. The post hoc analysis was conducted using the Newman-Keuls test with the level of significance set at $5 \%$.

Results

The frequency distribution of the final sample is shown in Table 2, according to the variables used in the characterization of the normative Brazilian adults of both genders. 
The examination of the means (Table 3 ) demonstrated that both men and women distorted their current body size. Women overestimated their current body size more than men. Pearson's correlation coefficients between actual and current BMI measures were significantly positive and high for women $(\mathrm{r}=.81 ; \mathrm{p}<.01)$ and men $(\mathrm{r}=.84 ; \mathrm{p}<.01)$. ANOVA showed significant differences for gender $[\mathrm{F}(1,274)=45.48 ; \mathrm{p}<.001]$ and BMI class $[\mathrm{F}(2,274)=8.33 ; \mathrm{p}<.001]$.

Figure 1 demonstrates the differences of the discrepancy by gender and BMI class which were given by the differences between current and actual BMI, with positive (overestimation) or negative (underestimation) absolute values. Positive values indicate that the participants perceived themselves as larger than they actually were. Overestimation was found in all groups, except in men with normal BMI interval, who underestimated their body size as represented by negative values.

The examination of body image dissatisfaction (Figure 2), considered as the difference between the

Table 2. Frequency distribution of the adult sample $(n=280)$ according to its social demographic variables.

\begin{tabular}{lcc}
\hline \multirow{2}{*}{ Variables } & Female & Male \\
\cline { 2 - 3 } BMI class & $\boldsymbol{n}(\boldsymbol{\%})$ & $\boldsymbol{n}(\mathbf{\%})$ \\
\hline Eutrophic & $58(48.03)$ & $58(41)$ \\
Overweight & $51(37)$ & $48(34)$ \\
Obese & $29(21)$ & $36(25)$ \\
\hline Age (years) & & \\
\hline 18 - 30 & $70(50.72)$ & $82(57.75)$ \\
31 - 40 & $43(31.16)$ & $35(24.65)$ \\
41 - 59 & $25(18.12)$ & $25(17.60)$ \\
\hline Social economic status & & \\
\hline A1 + A2 & $12(8.7)$ & $30(21.31)$ \\
B1 + B2 & $42(30.44)$ & $54(38.03)$ \\
C & $63(45.65)$ & $51(35.92)$ \\
D & $21(15.22)$ & $7(4.93)$ \\
\hline Educational level & & \\
\hline Primary & $49(36)$ & $19(13.5)$ \\
Secondary & $54(39)$ & $77(54)$ \\
College & $35(25)$ & $46(32.5)$ \\
\hline Total sample $(n=280)$ & $138(49.29)$ & $142(50.71)$ \\
\hline & & \\
\hline & & \\
\hline & & \\
\hline
\end{tabular}

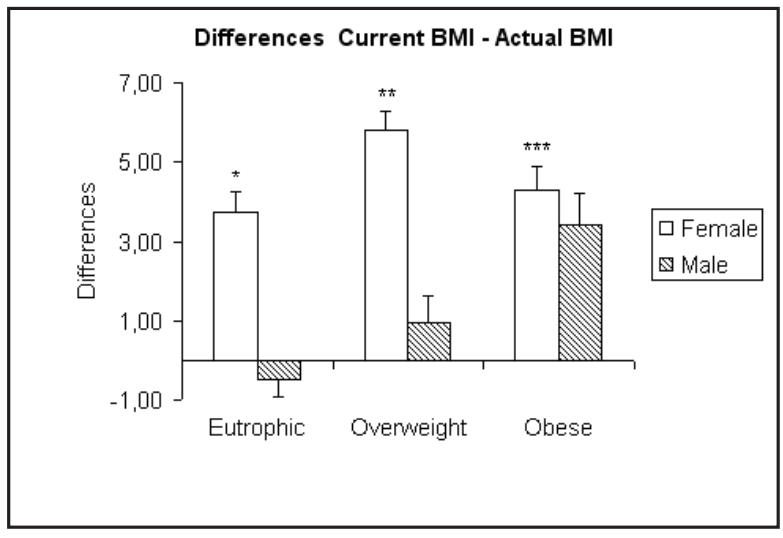

Figure 1. Body size discrepancy (overestimation and underestimation) given by the differences between current and actual BMI, by gender and BMI class. Bars represent the SEM. $* p<.05$ compared to overweight women and $p<.01$ compared to eutrophic and overweight men. $* * \mathrm{p}<.05$ compared to eutrophic women and men of all classes. $* * * \mathrm{p}<.001$ compared to eutrophic and overweight men.

desired and current BMI, also revealed significant differences for gender $[\mathrm{F}(2,274)=9.81 ; \mathrm{p}<.01]$, BMI class $[F(2,274)=67.18 ; p<.001]$ and the interaction of both factors $[F(2,274)=2.96 ; p<.05]$. In spite of the different magnitudes, all participants of this study were dissatisfied with their body size, desiring to be thinner than they thought they were, and this was true even for eutrophic male participants.

\section{Discussion}

The Figure Rating Scale has been usually used to evaluate body dissatisfaction alone (Fingeret et al., 2004). In this study, the psychometric qualities of the scale we used also enabled the evaluation of the body image discrepancy by the difference between the current and actual body size perception. The scale presented a test-retest reliability of $.93(\mathrm{p}<.01)$ for current BMI and a correlation coefficient of

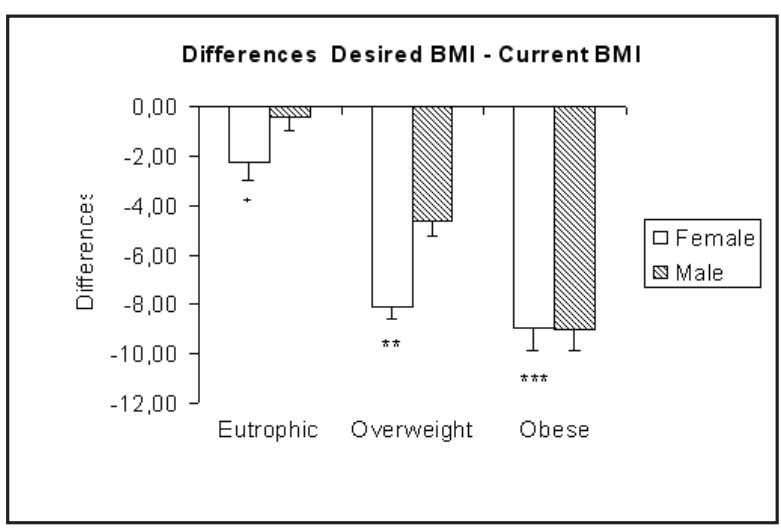

Figure 2. Body dissatisfaction given by the difference between desired and actual BMI, by gender and BMI class. Bars represent the SEM. ${ }^{*} \mathrm{p}<.05$ compared to women and men of all other BMI classes. $* * \mathrm{p}<.01$ compared to other classes except obese women and men. $* * * \mathrm{p}<.001$ compared to eutrophic women and men, and overweight men. 
Table 3. Descriptive data of the adult sample $(n=280)$ by gender, related to weight, height, actual BMI, and the perceived figures BMI as current, desired and ideal for the own and the opposite gender.

\begin{tabular}{|c|c|c|c|c|c|c|c|}
\hline & Weight & Height & & & BMI (k & & \\
\hline & $(\mathrm{kg})$ & $(\mathrm{m})$ & Actual & Current & Desired & Fem Ideal & Mal Ideal \\
\hline \multicolumn{8}{|c|}{ Female $n=138$} \\
\hline Mean & 68.22 & 1.61 & 26.47 & 31.01 & 25.25 & 24.11 & 23.30 \\
\hline Median & 66.7 & 1.61 & 26.22 & 32.50 & 25 & 25 & 22.50 \\
\hline SD & 12.69 & .06 & 4.61 & 6.35 & 4.52 & 3.98 & 3.75 \\
\hline SEM & 1.08 & .005 & .39 & .54 & .39 & .34 & .32 \\
\hline \multicolumn{8}{|c|}{$\underline{\text { Male }} n=142$} \\
\hline Mean & 82.27 & 1.75 & 26.98 & 27.98 & 23.94 & 24.68 & 23.35 \\
\hline Median & 78.70 & 1.75 & 26.08 & 26.25 & 22.50 & 25 & 22.5 \\
\hline SD & 15.72 & .07 & 4.85 & 7.73 & 4.62 & 3 & 3.69 \\
\hline SEM & 1.32 & .006 & .41 & .65 & .39 & .25 & .31 \\
\hline
\end{tabular}

$.84(\mathrm{p}<.01)$ between actual and current BMI measured in two different moments (Kakeshita, 2008).

The results concerning body image discrepancies are in agreement with previous findings. Women in general overestimate their body size more than men (Laus, Zancul, Martins, Kakeshita \& Almeida, 2006; Steenhuis et al., 2006; Bessenoff \& Snow, 2006), and overweight or pre-obese women present the highest levels of body size overestimation in relation to normal and obese women and men. One possible explanation for this finding is that pre-obese women are more likely to be vulnerable to body shame, as they have not been classified as obese yet, but are far from the sociocultural standard of beauty and successful woman body size and shape. By overestimating their body sizes, they could express the consciousness of not being within the healthy and recommended nutritional status.

Additionalstudiesinordertoexaminethecurrentbody self perception in relation to biological, psychological, and social factors are needed. They are particularly important when it comes to overweight people who are more vulnerable to emotional consequences such as shame and inadequate eating behavior reactions. These people tend to fail to join health programs to prevent obesity and related co-morbidities before becoming actually obese (Brownell \& Rodin, 1994; Wadden, Brownell \& Foster, 2002; Bernardi, Cichelero \& Vitolo, 2005; Kakeshita \& Almeida, 2006).

Regarding body image dissatisfaction, our results reinforce previous findings showing that females present greater body dissatisfaction than males (Van Den Berg et al., 2007; Neighbors \& Sobal, 2007). Van Den Berg et al. (2007) showed that males and females are dissatisfied with their bodies, but quite differently affected by the variables which mediate body dissatisfaction. Similarly, Lynch et al.
(2008) found that body dissatisfaction is present in both males and females, and it is a highly significant mediator of the relationship between BMI, body size, risky weight control behaviors, and vulnerability to eating disorders.

On the other hand, the worldwide prevalence of overweight and obesity has led people to search for an attainable normative body size and shape. However, the normative condition is quite close to overweight, despite the recommendations of a healthy body size (Donath, 2000).

Finally, further studies are needed to better understand the processes and variables related to body image, body discrepancy, and body dissatisfaction. The remaining question is how these findings can help us elaborate preventive actions and public health programs, in order to provide people with a better quality of life.

\section{Acknowledgment}

Research supported by grants from the National Council for Scientific and Technological Development (CNPq).

\section{References}

Bernardi, F., Cichelero, C., \& Vitolo, M.R. (2005). Restrained eating behavior and obesity. Brazilian Journal of Nutrition, 18(1), 85-93.

Bessenoff, G.R., \& Snow, D. (2006). Absorbing society's influence: Body image self-discrepancy and internalized shame. Sex Roles, $54,727-731$.

Brownell, K.D., \& Rodin, J. (1994). The Dieting Maelstrom - Is it possible and advisable to lose weight? American Psychologist, 49(9), 781-791.

Cachelin, F.M., Monreal, T.K., \& Juarez, L.C. (2006). Body image and size perception of Mexican American women. Body Image, 3, 67-75.

Cash, T.F. (2004). Body image: Past, present, and future. Body Image, 1, 1-5.

Damasceno, V.O., Lima, J.R.P., Vianna, J.M., Vianna, V.R.A., \& Novaes, J.S. (2005). Tipo físico ideal e satisfação com a imagem corporal de praticantes de caminhada. Revista Brasileira de Medicina do Esporte, 11(3), 181-186. 
Donath, S.M. (2000). Who's overweight? Comparison of the medical definition and community views. MJA-Medical Journal Australian, 172(8), 375-377.

Fingeret, M.C., Gleaves, D.H., \& Pearson, C.A. (2004). On the methodology of body image assessment: the use of figural rating scales to evaluate body dissatisfaction and the ideal body standards of women. Body Image, 1, 207-212.

Instituto Brasileiro de Geografia e Estatística (IBGE). (2004). Pesquisa de Orçamento Familiar (POF) 2002-2003: primeiros resultados: Brasil e grandes regiões. Análise da disponibilidade domiciliar de alimentos e do Estado Nutricional no Brasil. Available online at: <http://www.ibge.gov.br> Accessed in: 02 jun. 2008.

Kakeshita, I.S., \& Almeida, S.S. (2006). Relationship between body mass index and self-perception among university students. Revista de Saúde Pública, 40(3), 497-504.

Kakeshita, I.S. (2008). Adaptation and validation of a Figure Rating Scale for Brazilian children and adults. 2008. Doctoral Thesis, Faculdade de Filosofia Ciências e Letras de Ribeirão Preto, Universidade de São Paulo.

Laus, M.F., Zancul, M.S., Martins, T.M., Kakeshita, I.S., \& Almeida, S.S. (2006). Percepção da imagem corporal e estado nutricional em estudantes de nutrição. Alimentos e Nutrição, 17(1), 85-89.

Legenbauer, T., Rühl, I., \& Vocks, S. (2008). Influence of appearancerelated TV commercials on body image state. Behavior Modification, $32,352-370$

Lynch, W.C., Heil, D.P., Wagner, E., \& Havens, M.D. (2008). Body dissatisfaction mediates the association between body mass index and risky weight control behaviors among White and Native American adolescent girls. Appetite, 51, 210-213.

Matos, M.I.R, Aranha, L.S, Faria, A.N., Ferreira, S.R.G., Bacaltchuck, J., \& Zanella, M.T. (2002). Binge eating disorder, anxiety, depression and body image in grade III obesity patients. Revista Brasileira de Psiquiatria, 24(4), 165-169.

McCabe, M.P., Ricciardelli, L.A., Sitaram, G., \& Mikhail, K. (2006). Accuracy of body size estimation: Role of biopsychosocial variables. Body Image, 3(2), 163-171.

Neighbors, L.A., \& Sobal, J. (2007). Prevalence and magnitude of body weight and shape dissatisfaction among university students.
Eating Behaviors, 8, 429-439.

Sánchez-Johnsen, L.A.P., Hogan, K.., Wilkens, L.R., \& Fitzgibbon, M.L. (2008). Correlates of problematic eating behaviors in less acculturated Latinas. Eating Behaviors, 9, 181-189.

Steenhuis, I.H.M., Bos, A.E.R., \& Mayert, B. (2006). (Mis) interpretation of body weight in adult women and men. Journal of Human Nutrition Dietetic, 19, 219-228.

Swami, V., Salem, N., Furnham, A., \& Tovée, M.J. (2008). Initial examination of the validity and reliability of the female photographic figure rating scale for body image assessment. Personality and Individual Differences. Available online at: $<$ www.sciencedirect.com $>$.

Tehard, B., Van Liere M.J., Com Nougué, C., \& Clavel-Chapelon, F. (2002). Anthropometric measurements and body silhouette of women: Validity and perception. Journal of the American Dietetic Association, 102(12), 1779-1784.

Thompson, J.K. (1996). Assessing body image disturbance: measures, methodology, and implement. In: Thompson, J.K. (Ed.). Body image, eating disorders, and obesity: an integrative guide for assessment and treatment. (pp. 51-61). Washington, D.C.: American Psychological Association.

Thompson, J. K. (2004). The (mis)measurement of body image: Ten strategies to improve assessment for applied and research purposes. Body Image, 1, 7-14.

Van Den Berg, P., Paxton, S.J., Keery, H., Wall, M., Guo, J., \& Neumark-Sztainer, D. (2007). Body dissatisfaction and body comparison with media images in males and females. Body Image, 4, 257-268.

Vander Wal, J.S., \& Thomas, N. (2004). Predictors of body image dissatisfaction and disturbed eating attitudes and behaviors in African American and Hispanic girls. Eating Behavior, 5, 291-301.

Wadden, T.A., Brownell, K.D., \& Foster, G.D. (2002). Obesity: Responding to the global epidemic. Journal of Consulting and Clinical Psychology, 70(3), 510-525.

World Health Organization (WHO). (1997). Obesity: Preventing and managing the global epidemic. Report on WHO Consultation on Obesity. Geneve. 